\title{
Longterm Safety of Tocilizumab: Results from 3 Years of Followup Postmarketing Surveillance of 5573 Patients with Rheumatoid Arthritis in Japan
}

\author{
Kazuhiko Yamamoto, Hajime Goto, Kenzo Hirao, Atsuo Nakajima, Hideki Origasa, \\ Kunihiko Tanaka, Minako Tomobe, and Kyoichi Totsuka
}

\begin{abstract}
Objective. To evaluate the longterm safety of tocilizumab (TCZ) for the treatment of rheumatoid arthritis (RA) in a real-world clinical setting in Japan.

Methods. In this longterm extension of a single-arm, observational postmarketing surveillance study, a total of 5573 patients who initiated intravenous TCZ between April 2008 and July 2009 were observed for 3 years, regardless of its continuation, for incidence of fatal events, serious infections, malignancy, gastrointestinal perforations, and serious cardiac dysfunction.

Results. Of the 5573 patients who were enrolled, 4527 patients $(81.23 \%)$ completed 3 years of followup. There were no increases in the proportions of patients with fatal events, serious infection, malignancy, GI perforation, or serious cardiac dysfunction over 3 years. The all-cause mortality rate during followup was $2.58 \%$ (0.95/100 patient-yrs), and the standardized mortality ratio was 1.27 (95\% CI, 1.08 to 1.50). Patients who were older with longer disease duration and respiratory comorbidities were more likely to discontinue TCZ treatment following serious infection during the first year. Among patients who completed 3 years of TCZ treatment, serious infection developed at a constant rate during the 3-year treatment period. The proportion of malignancy during followup was $2.24 \%(0.83 / 100$ patient-yrs), and the standardized incidence ratio was 0.79 (95\% CI, 0.66 to 0.95$)$.

Conclusion. The safety profile of TCZ was consistent over time regarding mortality, serious infections, malignancy, gastrointestinal perforation, and serious cardiac dysfunction. These data confirm the longterm safety of TCZ use in patients with RA in a real-world clinical setting. (First Release June 1 2015; J Rheumatol 2015;42:1368-75; doi:10.3899/jrheum.141210)
\end{abstract}

Key Indexing Terms:

RHEUMATOID ARTHRITIS

TOCILIZUMAB

\section{POSTMARKETING PRODUCT SURVEILLANCE} INTERLEUKIN 6
From the Department of Allergy and Rheumatology, Graduate School of Medicine, The University of Tokyo; Department of Respiratory Medicine, Fukujuji Hospital; Heart Rhythm Center, Tokyo Medical and Dental University; Department of Rheumatology, Tokyo Metropolitan Police Hospital, Tokyo; Division of Biostatistics and Clinical Epidemiology, University of Toyama School of Medicine, Toyama; Chugai

Pharmaceutical Co. Ltd.; Department of Internal Medicine, Kitatama Hospital, Tokyo, Japan.

Funded by Chugai Pharmaceutical Co. Ltd. Data were collected and analyzed by Chugai according to a prespecified protocol. Support for third-party writing assistance for this manuscript, furnished by Eric Deutsch, PhD, was provided by F. Hoffmann-La Roche Ltd.

K. Yamamoto, MD, PhD, Department of Allergy and Rheumatology, Graduate School of Medicine, The University of Tokyo; H. Goto, MD, PhD, Department of Respiratory Medicine, Fukujuji Hospital; K. Hirao, MD, PhD, Heart Rhythm Center, Tokyo Medical and Dental University; A. Nakajima, MD, PhD, Department of Rheumatology, Tokyo Metropolitan Police Hospital; H. Origasa, PhD, Division of Biostatistics and Clinical Epidemiology, University of Toyama School of Medicine; K. Tanaka, MSc; M. Tomobe, BPharm, Chugai Pharmaceutical Co. Ltd.; K. Totsuka, MD, PhD, Department of Internal Medicine, Kitatama Hospital.

Address correspondence to Dr. K. Yamamoto, MD, PhD, Department of Allergy and Rheumatology, Graduate School of Medicine, The University of Tokyo, 7-3-1 Hongo, Bunkyo-ku, Tokyo 113-8655, Japan.

E-mail: yamamoto-tky@umin.ac.jp

Full Release Article. For details see Reprints/Permissions at jrheum.org Accepted for publication March 31, 2015.
The humanized antiinterleukin 6 receptor monoclonal antibody tocilizumab (TCZ) has been demonstrated in phase III clinical studies to improve disease activity and inhibit progression of joint destruction in patients with rheumatoid arthritis (RA) ${ }^{1,2,3,4,5,6,7}$. Adverse events (AE) of interest were identified for patients receiving TCZ, including serious infections, malignancy, gastrointestinal (GI) perforations, and cardiac dysfunction ${ }^{8}$. On the basis of these results, TCZ received marketing approval for patients with RA in more than 100 countries. Upon approval, the initial safety and effectiveness of TCZ in the Japanese real-world clinical setting were evaluated in the all-patient postmarketing surveillance (PMS) program with a 28-week followup period $^{9}$. Results of this PMS showed that the overall incidence rate of serious infections was comparable with that of phase III studies, and patients with more risk factors [age $>65 \mathrm{yrs}$, disease duration $\geq 10 \mathrm{yrs}$, previous or concurrent respiratory disease, and concomitant corticosteroid dose $>5$ $\mathrm{mg} /$ day (prednisolone equivalent)] had a higher incidence of serious infections. This report presents the mortality rates and incidence of $\mathrm{AE}$ of special interest in 5573 patients with RA

Personal non-commercial use only. The Journal of Rheumatology Copyright $\odot$ 2015. All rights reserved 
who received $\geq 1$ dose of intravenous TCZ in the 3-year longterm extension of the all-patient PMS program.

\section{MATERIALS AND METHODS}

Patients. This report refers to the 3-year extension to the 28-week all-patient PMS program evaluating intravenous TCZ in patients with RA in Japan ${ }^{9}$. This longterm extension study was mandated by the Japanese Health Authority, as was the initial all-patient PMS. We asked all 992 institutions included in the all-patient PMS to participate and 707 agreed. Patients who initiated TCZ treatment in these participating institutions by July 2009 were enrolled in this 3-year followup study.

Protocol. The PMS study protocol has been described ${ }^{9}$. Information on the development of fatal events, serious infections, malignancies, GI perforations, and serious cardiac dysfunction was collected from case report forms and coded using the Medical Dictionary for Regulatory Activities (version 16.1). To maximize participation from eligible institutions and obtain information for the duration of the 3-year followup period, case report forms were simplified to focus on the aforementioned $\mathrm{AE}$ of interest; therefore, information on other events was not collected. The study data were analyzed jointly with data from the all-patient $\mathrm{PMS}^{9}$. Patients who received $\geq 1$ dose of intravenous TCZ were analyzed 2 different ways: (1) patients were observed for 3 years from the initial dose of TCZ, regardless of whether treatment was continued (defined as the "observational followup period"), and (2) patients were observed as long as TCZ treatment was continued during the 3 years of followup (defined as the "TCZ treatment period"). The incidences of mortality, serious infection, malignancy, GI perforation, and serious cardiac dysfunction were evaluated and summarized.

Statistical analysis. Data were summarized as the proportion $(95 \%$ CI) of patients experiencing each event or as incidence rates presented as the number of patients per 100 patient-years. For patients who died, were transferred, or were otherwise lost to followup, the followup period included all data available prior to the date of death or the last hospital visit. In patients who experienced multiple events (e.g., $>1$ serious infection or $>1$ malignancy), all events were recorded and analyzed as part of each observational period.
The standardized mortality ratio (SMR) was calculated using the 2012 database of the Ministry of Health, Labor, and Welfare for mortality rates in the general Japanese population. The standardized incidence ratio (SIR) was calculated using the 2008 data for cancer incidence in Japan published by the Center for Cancer Control and Information Services at the National Cancer Center. The SMR and SIR (and corresponding 95\% CI) were calculated by indirect methods using an approximate Poisson distribution. Comparison of the characteristics of patients who developed serious infections and continued or discontinued TCZ treatment were investigated using the $t$ test and the chi-squared test. Risk factors for GI perforation were investigated using univariate logistic regression analyses.

\section{RESULTS}

Patients. As of April 2013, 5620 patients were enrolled and 5573 patients were followed in this longterm extension for a total duration of observation of 15,106 patient-years (Figure 1). Overall, the baseline characteristics of patients followed in the longterm extension closely matched those of patients followed in the initial PMS ${ }^{9} ; 4542$ patients $(81.5 \%)$ were female and the mean age was 58.7 years (Table 1). The cumulative exposure to TCZ was 11,734 patient-years, and the mean (SD) and median (interquartile range) treatment durations were 2.1 (1.1) and 2.9 (1.0-3.0) years, respectively. Excluding patients who died, transferred hospitals, or were lost to followup, a total of 5327 (95.59\%) patients completed 1 year, 4850 (87.03\%) patients completed 2 years, and 4527 (81.23\%) patients completed 3 years of observation; 2721 patients $(48.82 \%)$ continued TCZ treatment for $>152$ weeks. Safety. The mortality rate during the followup period was $2.58 \%(0.95 / 100$ patient-yrs). It decreased over each year of observation (Figure 2A). The most common cause of death was infection $(28.47 \%)$, followed by respiratory disease

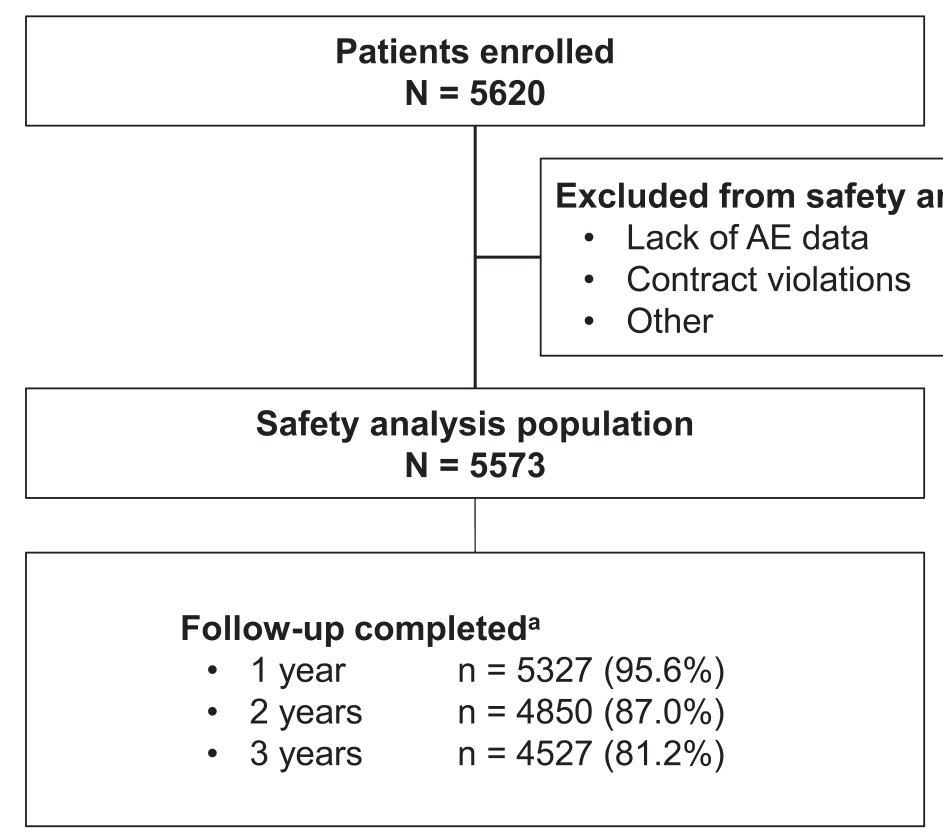

Figure 1. Patient flow in the 3-year longterm extension of the all-patient PMS program. ${ }^{\mathrm{a} E x c l u d i n g}$ patients who died, transferred hospitals, or were otherwise lost to followup. PMS: postmarketing surveillance; AE: adverse event. 
Table 1. Baseline demographic and disease characteristics of patients with rheumatoid arthritis participating in the PMS study of TCZ in Japan.

\begin{tabular}{|c|c|}
\hline Characteristics & atients Receiving TCZ, $\mathrm{n}=5573$ \\
\hline \multicolumn{2}{|l|}{ Demographics } \\
\hline Female, n $(\%)$ & $4542(81.5)$ \\
\hline Age, yrs, mean (SD) & $58.7(12.8)$ \\
\hline Median, yrs, (range) & $60.0(16-91)$ \\
\hline$\geq 65$ yrs, $\mathrm{n}(\%)$ & $2019(36.23)$ \\
\hline Body weight, mean (SD), $\mathrm{kg}$ & $53.3(10.3)$ \\
\hline Disease duration, mean (SD), yrs & $10.5(9.2)$ \\
\hline Median (range), yrs & $7.9(0.0-61.9)$ \\
\hline$\geq 10 \mathrm{yrs}, \mathrm{n}(\%)$ & $2149(38.56)$ \\
\hline \multicolumn{2}{|l|}{ Medical history, n (\%) } \\
\hline Infections & $647(11.61)$ \\
\hline Malignancy & $217(3.89)$ \\
\hline Cardiac dysfunction & $184(3.30)$ \\
\hline \multicolumn{2}{|l|}{ History of comorbidities, n (\%) } \\
\hline GI tract disturbance & $1177(21.12)$ \\
\hline Respiratory disease & $864(15.50)$ \\
\hline Diabetes mellitus & $585(10.50)$ \\
\hline Hepatic disorder & $401(7.20)$ \\
\hline Cardiac dysfunction & $364(6.53)$ \\
\hline Renal dysfunction & $313(5.62)$ \\
\hline Malignancy & $32(0.57)$ \\
\hline \multicolumn{2}{|l|}{ Clinical characteristics } \\
\hline \multicolumn{2}{|l|}{ Steinbrocker radiographic stage, n (\%) } \\
\hline Stage I & $440(7.90)$ \\
\hline Stage II & $1480(26.56)$ \\
\hline Stage III & $1778(31.90)$ \\
\hline Stage IV & $1875(33.64)$ \\
\hline \multicolumn{2}{|l|}{ Steinbrocker functional class, n (\%) } \\
\hline Class 1 & $664(11.91)$ \\
\hline Class 2 & $3439(61.71)$ \\
\hline Class 3 & $1429(25.64)$ \\
\hline Class 4 & $40(0.72)$ \\
\hline Previous use of biologics, n (\%) & $3502(62.84)$ \\
\hline Baseline DMARD use, n (\%) & 3867 (69.39) \\
\hline Baseline MTX use, n (\%) & $2972(53.33)$ \\
\hline MTX dose $>8 \mathrm{mg} /$ week, $\mathrm{n}(\%)$ & $460(8.25)$ \\
\hline Baseline steroid use (oral and IV), n (\%) & $4156(74.57)$ \\
\hline $\begin{array}{l}\text { Steroid (oral and IV) dose }>5 \mathrm{mg} / \mathrm{da} \\
\mathrm{n}(\%)\end{array}$ & $1532(27.49)$ \\
\hline
\end{tabular}

DMARD: disease-modifying antirheumatic drug; GI: gastrointestinal; IV: intravenous; MTX: methotrexate; PMS: postmarketing surveillance; TCZ: tocilizumab.

(15.97\%), malignancy (14.58\%), cardiac dysfunction (9.03\%), and cerebrovascular disorder (5.56\%). The SMR in this study, in comparison with the general Japanese population, was 1.27 (95\% CI, 1.08 to 1.50$)$.

The overall incidences of serious infection during the followup period and the TCZ treatment period were $9.94 \%$ (3.67/100 patient-yrs) and 8.56\% (4.07/100 patient-yrs), respectively. The proportion of patients with serious infections did not increase from the first year to the second and third years (Figure 2B). Of the patients who developed serious infections in the first year, $57.59 \%$ (182/316 patients) discontinued TCZ treatment. Compared with patients who continued TCZ treatment after experiencing serious infection, the patients who developed serious infections and discontinued TCZ treatment in the first year were older (mean, 66.3 vs 59.4 yrs; $\mathrm{p}<0.01)$, had non-significantly longer disease duration (13.3 vs 11.4 yrs), and were non-significantly more likely to have respiratory comorbidities $(33.5 \%$ vs $28.4 \%$ ). Except for the discontinued cases or those lost to followup, the proportion of patients with serious infection was generally stable over time during the TCZ treatment period (Figure 3). The most common serious infection was bacterial pneumonia (Table 2). Patients who were biologic-experienced had a similar incidence of serious infection compared with patients who were biologic-naive [8.31\% (291/3502 patients) vs $8.98 \%$ (186/2071 patients); $\mathrm{p}=0.3865]$.

Malignancies were reported in $2.24 \%$ (0.83/100 patient-yrs) of patients during the followup period, with an overall SIR of 0.79 (95\% CI, 0.66 to 0.95 ) in 117 patients with nonrecurring or non-metastatic malignancies. Only malignant lymphoma had a significantly higher incidence compared with the general Japanese population (Table 3). The proportion of patients with malignancy was stable over time during the followup period (Figure 2C).

The overall incidence of GI perforation during the followup period was $0.65 \%(0.24 / 100$ patient-yrs $)$, which did not increase over time (Figure 2D). Univariate regression analysis for GI perforation suggested that male sex; Steinbrocker functional classification; complications or medical history of diverticulum, amyloidosis, and GI ulcers; and baseline dose of glucocorticoids (mg/day, prednisolone or equivalent) may increase the risk of GI perforation (Appendix 1).

Serious cardiac dysfunction was reported in $1.11 \%$ $(0.41 / 100$ patient-yrs $)$ of patients, including heart failure $[0.47 \%(0.17 / 100$ patient-yrs $)]$ and ischemic heart disease $[0.43 \%(0.16 / 100$ patient-yrs $)]$. Myocardial infarction $[0.20 \%$ $(0.07 / 100$ patient-yrs) $]$ and angina pectoris $[0.16 \%(0.06 / 100$ patient-yrs)] were the most common disorders related to ischemic heart disease. The proportion of patients with serious cardiac dysfunction did not increase during followup (Figure 2E). Of the 34 patients who developed serious cardiac dysfunction in the first year, 7 patients (20.59\%) subsequently died and 4 patients $(11.76 \%)$ were lost to followup for other reasons.

A total of 5573, 4208, and 3462 patients were observed during the $>0$ to 12 months, $>12$ to 24 months, and $>24$ to 36 months TCZ treatment periods, respectively. Overall, the incidence of each event category from year to year during the TCZ treatment period was comparable with that during the followup period (Figure 2).

\section{DISCUSSION}

We evaluated the mortality rate and the incidences of serious infection, malignancy, GI perforation, and serious cardiac dysfunction during the 3-year followup after TCZ initiation in Japanese patients with RA.

Personal non-commercial use only. The Journal of Rheumatology Copyright @ 2015 . All rights reserved. 
A

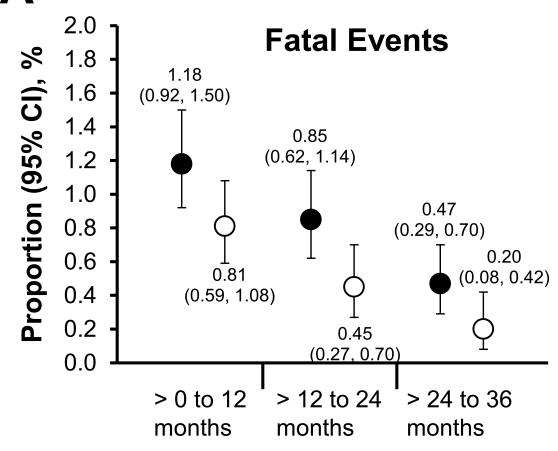

C

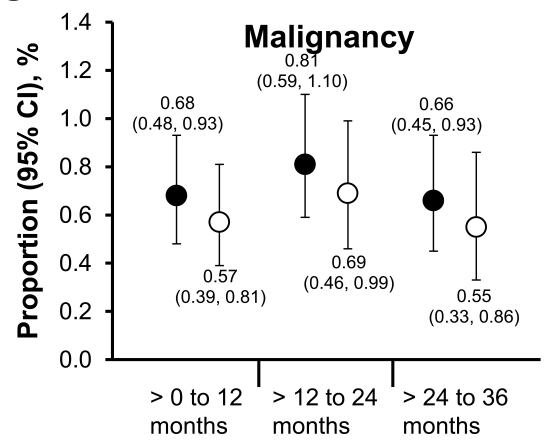

E

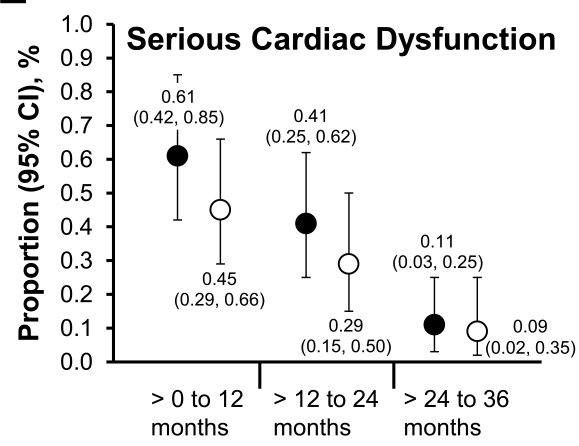

B

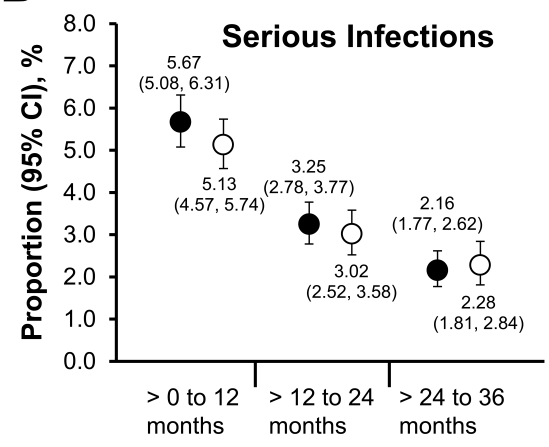

D

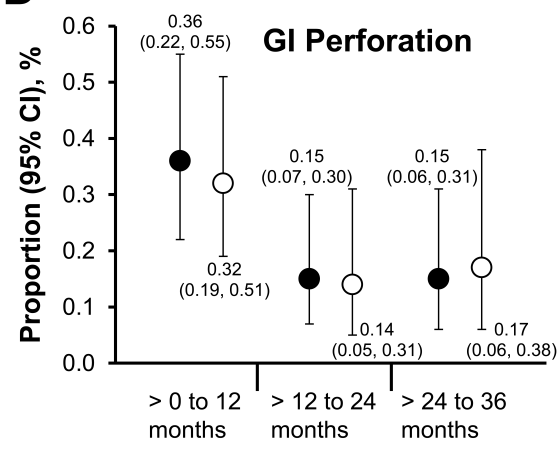

Observational follow-up period

TCZ-treatment period

Figure 2. Changes in the proportion (95\% CI) of patients with (A) fatal events, (B) serious infections, (C) malignancy, (D) GI perforation, and (E) serious cardiac dysfunction during each year of the observational followup period and the TCZ treatment period. Overall, 5573, 5168, and 4721 patients were observed during the $>0$ to 12 months, $>12$ to 24 months, and $>24$ to 36 months followup periods, respectively, while 5573, 4208, and 3462 patients were followed during the same intervals of TCZ treatment. GI: gastrointestinal; TCZ: tocilizumab.

The SMR (95\% CI) in our study [1.27 (1.08 to 1.50)] was similar to the SMR reported in the initial all-patient PMS [1.15 (0.83 to 1.61$)]$ and in those reported in a large observational cohort of Japanese patients with RA [between 1.46 (1.32 to 1.60$)$ and $1.90(1.75$ to 2.07$)]^{9,10}$. There were no concerns of increased risk of mortality associated with TCZ treatment.

The overall incidence of serious infection during the followup period of this study was $3.67 / 100$ patient-years, which was found to be similar to the results of the initial all-patient PMS and longterm safety cumulative analyses of phase III clinical trials $(4.5 / 100$ patient-yrs to $9.0 / 100$ patient-yrs, respectively) $)^{8,9,11}$. With regard to incidence of infections, prior $\mathrm{AE}$ and presence of additional risk factors for infection (e.g., advanced age, long disease duration, and respiratory comorbidities) could be reasons for discontinuation of TCZ. Notably, about half the patients who developed serious infections within the first year of initiating TCZ treatment and who had subsequently discontinued treatment were older, had longer disease duration, and had more respiratory comorbidities compared with patients who had a presumed lower risk of serious infection and remained in the

Personal non-commercial use only. The Journal of Rheumatology Copyright @ 2015 . All rights reserved. 


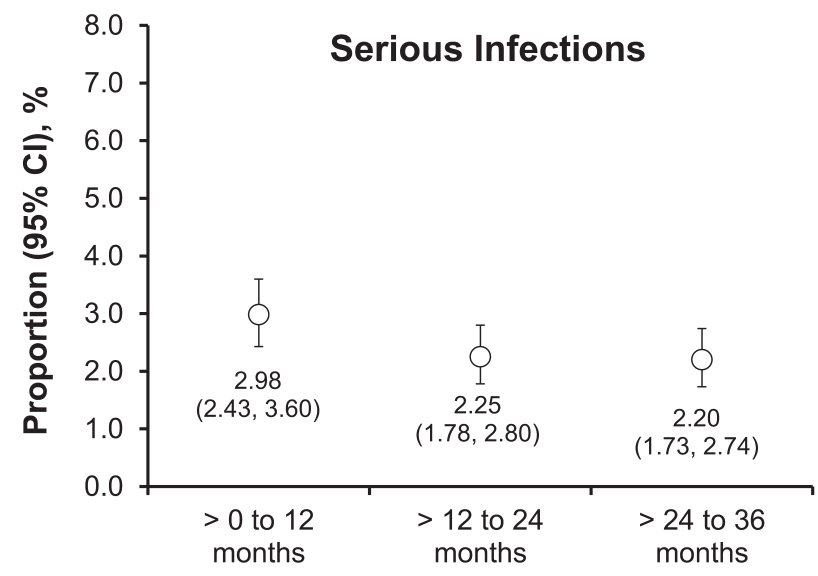

Figure 3. Change in the proportion $(95 \% \mathrm{CI})$ of patients with serious infections during each year of the TCZ treatment period, except for discontinuation cases and those lost to followup. $\mathrm{N}=3462$ during each of the TCZ treatment periods: $>0$ to 12 months, $>12$ to 24 months, and $>24$ to 36 months. TCZ: tocilizumab.

analysis during the second and third years. Because serious infections developed at a constant rate in the patients who continued TCZ treatment, discontinuation of TCZ may have reduced the risk of serious infection. Careful monitoring of infections is needed to prevent escalation or occurrence of serious infections at any time during TCZ treatment.

Malignant lymphoma occurs with a significantly higher incidence in patients with RA compared with the general population ${ }^{12}$. The SIR for malignancies in our study were lower than those reported to date in a large cohort of Japanese patients with $\mathrm{RA}^{13}$. The SIR for malignant lymphoma in the current study were not higher than those in biologic-experienced Japanese patients with RA reported by the Japan College of Rheumatology ${ }^{14}$. On the basis of these results, exposure to TCZ did not appear to influence the occurrence of malignancy.

Lower GI perforations are rare, but serious complications of TCZ treatment appear to occur more frequently in patients receiving glucocorticoids ${ }^{15}$. The overall incidence of GI perforation in our study was comparable with reports from longterm extensions of TCZ randomized trials and did not increase over time ${ }^{8}$. Patients at a higher risk of GI perforations and who should be carefully monitored during TCZ therapy were male, had been treated with high-dose glucocorticoids, had higher Steinbrocker functional classification, and had complications or a medical history of diverticula, amyloidosis, or GI ulcers.

RA is associated with increased cardiovascular disease risk with multifactorial involvement of inflammation. Systematic literature reviews reported that anti-tumor necrosis factor agents and methotrexate (MTX) use were associated with a decreased cardiovascular risk in patients with RA ${ }^{16,17}$. In this study, the proportion of patients with serious cardiac dysfunction decreased over time. Some of this decreased risk may have been a result of continued use of MTX; however, the decrease may also have been partially attributable to loss of followup in some patients, possibly selecting for patients who did not leave the study for AE-related reasons. Further investigation is needed to thoroughly evaluate the influence of TCZ treatment on cardiovascular risk in patients with RA.

This study has some limitations. Firstly, because our case report forms were designed to maximize participation from a large number of institutions and were focused on specific $\mathrm{AE}$ of interest, we could obtain only minimal information for selected $\mathrm{AE}$ to measure the incidence of these events on a large scale. It was not feasible to collect more-detailed information on concomitant medications, such as corticosteroid use, from such a large number of patients. As a result, more in-depth analyses, such as identification of potential risk factors for $\mathrm{AE}$ of interest, stratification by concomitant medications, or detailed information on types of bacterial infection were beyond the scope of our study. Secondly, we were unable to follow a portion of the patients through the end of the 3-year followup period. Notably, 902 of the 5573 patients enrolled (16.2\%) failed to complete the 3-year

Table 2. Incidence rates of common serious infections during the followup period and TCZ treatment period, defined as the period of followup during which patients were receiving intravenous TCZ.

\begin{tabular}{|c|c|c|c|c|}
\hline \multirow[t]{2}{*}{ Site } & \multicolumn{2}{|c|}{$\begin{array}{c}\text { Followup Period, } \mathrm{n}=5573, \\
15,106 \text { Patient-yrs }\end{array}$} & \multicolumn{2}{|c|}{$\begin{array}{c}\text { TCZ Treatment Period, } \mathrm{n}=5573, \\
11,734 \text { Patient-yrs }\end{array}$} \\
\hline & $\mathrm{n}(\%)$ & $\begin{array}{c}\text { Rate per } 100 \\
\text { Patient-yrs }\end{array}$ & $\mathrm{n}(\%)$ & $\begin{array}{l}\text { Rate per } 100 \\
\text { Patient-yrs }\end{array}$ \\
\hline Serious infection, total & $554(9.94)$ & 3.67 & $477(8.56)$ & 4.07 \\
\hline Bacterial pneumonia & $180(3.23)$ & 1.19 & $150(2.69)$ & 1.28 \\
\hline Cellulitis & $66(1.18)$ & 0.44 & $64(1.15)$ & 0.55 \\
\hline Sepsis & $42(0.75)$ & 0.28 & $25(0.45)$ & 0.21 \\
\hline Atypical mycobacteriosis & $29(0.52)$ & 0.19 & $26(0.47)$ & 0.22 \\
\hline Pneumocystis jirovecii pneumonia & $20(0.36)$ & 0.13 & $14(0.25)$ & 0.12 \\
\hline Herpes zoster & $27(0.48)$ & 0.18 & $23(0.41)$ & 0.20 \\
\hline Tuberculosis & $8(0.14)$ & 0.05 & $5(0.09)$ & 0.04 \\
\hline
\end{tabular}

TCZ: tocilizumab. 
Table 3. Standardized incidence ratio (SIR) of malignancy by site during the followup period.

\begin{tabular}{|c|c|c|c|c|c|c|c|c|c|}
\hline \multirow[t]{2}{*}{ Site } & \multicolumn{3}{|c|}{ Total, $\mathrm{n}=5573$} & \multicolumn{3}{|c|}{ Male, $\mathrm{n}=1031$} & \multicolumn{3}{|c|}{ Female, $\mathrm{n}=4542$} \\
\hline & $\mathrm{n}$ & SIR & $95 \% \mathrm{CI}$ & $\mathrm{n}$ & SIR & $95 \% \mathrm{CI}$ & $\mathrm{n}$ & SIR & $95 \% \mathrm{CI}$ \\
\hline All sites & 117 & 0.79 & 0.66 to 0.95 & 35 & 0.85 & 0.61 to 1.18 & 82 & 0.98 & 0.79 to 1.21 \\
\hline Esophagus & 3 & 0.61 & 0.20 to 1.90 & 2 & 1.11 & 0.28 to 4.45 & 1 & 0.99 & 0.14 to 7.04 \\
\hline Stomach & 19 & 0.77 & 0.49 to 1.21 & 8 & 1.04 & 0.52 to 2.08 & 11 & 1.10 & 0.61 to 1.98 \\
\hline Colon/rectum & 8 & 0.30 & 0.15 to 0.59 & 3 & 0.41 & 0.13 to 1.27 & 5 & 0.34 & 0.14 to 0.81 \\
\hline Pancreas & 3 & 0.54 & 0.17 to 1.66 & 1 & 0.69 & 0.10 to 4.92 & 2 & 0.60 & 0.15 to 2.39 \\
\hline Lung, trachea & 15 & 0.80 & 0.48 to 1.32 & 8 & 1.35 & 0.67 to 2.70 & 7 & 0.87 & 0.41 to 1.82 \\
\hline Skin & 4 & 1.44 & 0.54 to 3.84 & 1 & 1.48 & 0.21 to 10.51 & 3 & 1.63 & 0.53 to 5.06 \\
\hline Breast & 17 & 0.76 & 0.48 to 1.20 & 0 & - & - & 17 & 0.93 & 0.59 to 1.47 \\
\hline Cervix uteri & 1 & - & - & - & - & - & 1 & 0.26 & 0.04 to 1.87 \\
\hline Corpus uteri & 4 & - & - & - & - & - & 4 & 1.17 & 0.44 to 3.12 \\
\hline Brain, nervous system & 2 & 2.30 & 0.57 to 9.18 & 0 & - & - & 2 & 3.28 & 0.82 to 13.13 \\
\hline Thyroid & 5 & 2.35 & 0.98 to 5.66 & 0 & - & - & 5 & 2.09 & 0.87 to 5.01 \\
\hline Malignant lymphoma & 13 & 3.13 & 1.82 to 5.39 & 3 & 2.90 & 0.93 to 8.98 & 10 & 3.89 & 2.09 to 7.22 \\
\hline Leukemia & 1 & 0.54 & 0.08 to 3.83 & 0 & - & - & 1 & 0.90 & 0.13 to 6.41 \\
\hline
\end{tabular}

followup because they transferred hospitals or were lost for other unknown reasons. Thirdly, while the patient characteristics of those who participated in this longterm study were similar to the patients who were enrolled in the initial 28-week all-patient PMS program, not all of the patients in the initial study were included in this longterm followup study. We had asked all 992 institutions included in the initial all-patient PMS to participate in this longterm followup study, to minimize bias; however, only 707 institutions agreed to participate. As a result, even though the baseline characteristics of patients were closely matched between the 2 studies, suggesting little effect on the results, there may still exist some small population bias.

To our knowledge, this is the first longterm PMS report of a biologic for patients with RA in a real-world clinical setting in Japan; therefore, there is no study that may serve as a true comparator. Other PMS studies have been conducted in patients with RA in Japan for infliximab, etanercept, and adalimumab $^{18,19,20}$. In each of those PMS studies, patients were followed for 6 months, compared with 3 years for the current followup study. It may not be appropriate to make direct comparisons for $\mathrm{AE}$ of interest because of these differences in length of followup. It should also be noted that the PMS studies for these other biologics were acknowledged and discussed in the initial PMS report for TCZ, which noted that risk factors for serious infections were similar across biologics ${ }^{9}$. The overall mortality rates and rates and/or proportions of patients with serious infections were also similar across biologics in the 6-month PMS studies (where reported). Although the definitions may have differed across studies, the rates of malignancies and serious cardiac dysfunction (e.g., cardiac failure and/or ischemic heart disease) were similar across biologics at 6 months. GI perforations are typically an AE of interest for TCZ treatment and were not investigated in PMS reports for other biologics.

The results from this study demonstrate that the safety profile of TCZ was consistent and did not worsen over time regarding mortality, serious infections, malignancy, GI perforation, and serious cardiac dysfunction. Whereas randomized controlled studies have assessed the longterm safety of TCZ in patients with RA, these data confirm, for the first time, the longterm safety of TCZ use in patients with RA in a real-world clinical setting ${ }^{11,21}$.

\section{ACKNOWLEDGMENT}

The authors thank all investigators for their contributions to the implementation of the study.

\section{REFERENCES}

1. Emery P, Keystone E, Tony HP, Cantagrel A, van Vollenhoven R, Sanchez A, et al. IL-6 receptor inhibition with tocilizumab improves treatment outcomes in patients with rheumatoid arthritis refractory to anti-tumour necrosis factor biologicals: results from a 24-week multicentre randomised placebo-controlled trial. Ann Rheum Dis 2008;67:1516-23.

2. Genovese MC, McKay JD, Nasonov EL, Mysler EF, da Silva NA, Alecock E, et al. Interleukin-6 receptor inhibition with tocilizumab reduces disease activity in rheumatoid arthritis with inadequate response to disease-modifying antirheumatic drugs: the tocilizumab in combination with traditional disease-modifying antirheumatic drug therapy study. Arthritis Rheum 2008;58:2968-80.

3. Jones G, Sebba A, Gu J, Lowenstein MB, Calvo A, Gomez-Reino $\mathrm{JJ}$, et al. Comparison of tocilizumab monotherapy versus

Personal non-commercial use only. The Journal of Rheumatology Copyright @ $\ 2015$. All rights reserved. 
methotrexate monotherapy in patients with moderate to severe rheumatoid arthritis: the AMBITION study. Ann Rheum Dis 2010;69:88-96

4. Kremer JM, Blanco R, Brzosko M, Burgos-Vargas R, Halland AM, Vernon E, et al. Tocilizumab inhibits structural joint damage in rheumatoid arthritis patients with inadequate responses to methotrexate: results from the double-blind treatment phase of a randomized placebo-controlled trial of tocilizumab safety and prevention of structural joint damage at one year. Arthritis Rheum 2011;63:609-21.

5. Smolen JS, Beaulieu A, Rubbert-Roth A, Ramos-Remus C, Rovensky J, Alecock E, et al. Effect of interleukin-6 receptor inhibition with tocilizumab in patients with rheumatoid arthritis (OPTION study): a double-blind, placebo-controlled, randomised trial. Lancet 2008;371:987-97.

6. Nishimoto N, Hashimoto J, Miyasaka N, Yamamoto K, Kawai S, Takeuchi T, et al. Study of active controlled monotherapy used for rheumatoid arthritis, an IL-6 inhibitor (SAMURAI): evidence of clinical and radiographic benefit from an $\mathrm{x}$ ray reader-blinded randomised controlled trial of tocilizumab. Ann Rheum Dis 2007;66:1162-7.

7. Nishimoto N, Miyasaka N, Yamamoto K, Kawai S, Takeuchi T, Azuma J, et al. Study of active controlled tocilizumab monotherapy for rheumatoid arthritis patients with an inadequate response to methotrexate (SATORI): significant reduction in disease activity and serum vascular endothelial growth factor by IL-6 receptor inhibition therapy. Mod Rheumatol 2009;19:12-9.

8. Schiff MH, Kremer JM, Jahreis A, Vernon E, Isaacs JD, van Vollenhoven RF. Integrated safety in tocilizumab clinical trials. Arthritis Res Ther 2011;13:R141.

9. Koike T, Harigai M, Inokuma S, Ishiguro N, Ryu J, Takeuchi T, et al. Effectiveness and safety of tocilizumab: postmarketing surveillance of 7901 patients with rheumatoid arthritis in Japan. J Rheumatol 2014;41:15-23.

10. Nakajima A, Inoue E, Tanaka E, Singh G, Sato E, Hoshi D, et al. Mortality and cause of death in Japanese patients with rheumatoid arthritis based on a large observational cohort, IORRA. Scand J Rheumatol 2010;39:360-7.

11. Genovese MC, Rubbert-Roth A, Smolen JS, Kremer J, Khraishi M, Gomez-Reino J, et al. Longterm safety and efficacy of tocilizumab in patients with rheumatoid arthritis: a cumulative analysis of up to 4.6 years of exposure. J Rheumatol 2013;40:768-80.
12. Smitten AL, Simon TA, Hochberg MC, Suissa S. A meta-analysis of the incidence of malignancy in adult patients with rheumatoid arthritis. Arthritis Res Ther 2008;10:R45

13. Yamada T, Nakajima A, Inoue E, Tanaka E, Taniguchi A, Momohara $\mathrm{S}$, et al. Incidence of malignancy in Japanese patients with rheumatoid arthritis. Rheumatol Int 2011;31:1487-92.

14. Harigai M, Nanki T, Koike R, Tanaka M, Watanabe K, Komano Y, et al. Biological agents in rheumatoid arthritis and risk of malignancy - results from the nation-wide cohort study in Japan [abstract]. Arthritis Rheum 2011;63 Suppl:S41.

15. Gout T, Ostor AJ, Nisar MK. Lower gastrointestinal perforation in rheumatoid arthritis patients treated with conventional DMARDs or tocilizumab: a systematic literature review. Clin Rheumatol 2011;30:1471-4.

16. Barnabe C, Martin BJ, Ghali WA. Systematic review and meta-analysis: anti-tumor necrosis factor alpha therapy and cardiovascular events in rheumatoid arthritis. Arthritis Care Res 2011;63:522-9.

17. Westlake SL, Colebatch AN, Baird J, Kiely P, Quinn M, Choy E, et al. The effect of methotrexate on cardiovascular disease in patients with rheumatoid arthritis: a systematic literature review. Rheumatology 2010;49:295-307.

18. Takeuchi T, Tatsuki Y, Nogami Y, Ishiguro N, Tanaka Y, Yamanaka $\mathrm{H}$, et al. Postmarketing surveillance of the safety profile of infliximab in 5000 Japanese patients with rheumatoid arthritis. Ann Rheum Dis 2008;67:189-94

19. Koike T, Harigai M, Inokuma S, Ishiguro N, Ryu J, Takeuchi T, et al. Postmarketing surveillance of safety and effectiveness of etanercept in Japanese patients with rheumatoid arthritis. Mod Rheumatol 2011;21:343-51.

20. Koike T, Harigai M, Ishiguro N, Inokuma S, Takei S, Takeuchi T, et al. Safety and effectiveness of adalimumab in Japanese rheumatoid arthritis patients: postmarketing surveillance report of 7740 patients. Mod Rheumatol 2014;24:390-8.

21. Nishimoto N, Miyasaka N, Yamamoto K, Kawai S, Takeuchi T, Azuma J. Long-term safety and efficacy of tocilizumab, an anti-IL-6 receptor monoclonal antibody, in monotherapy, in patients with rheumatoid arthritis (the STREAM study): evidence of safety and efficacy in a 5-year extension study. Ann Rheum Dis 2009; $68: 1580-4$ 
APPENDIX 1. Summary and predictors of gastrointestinal (GI) perforation estimated by univariate logistic regression analysis ${ }^{\mathrm{a}}$.

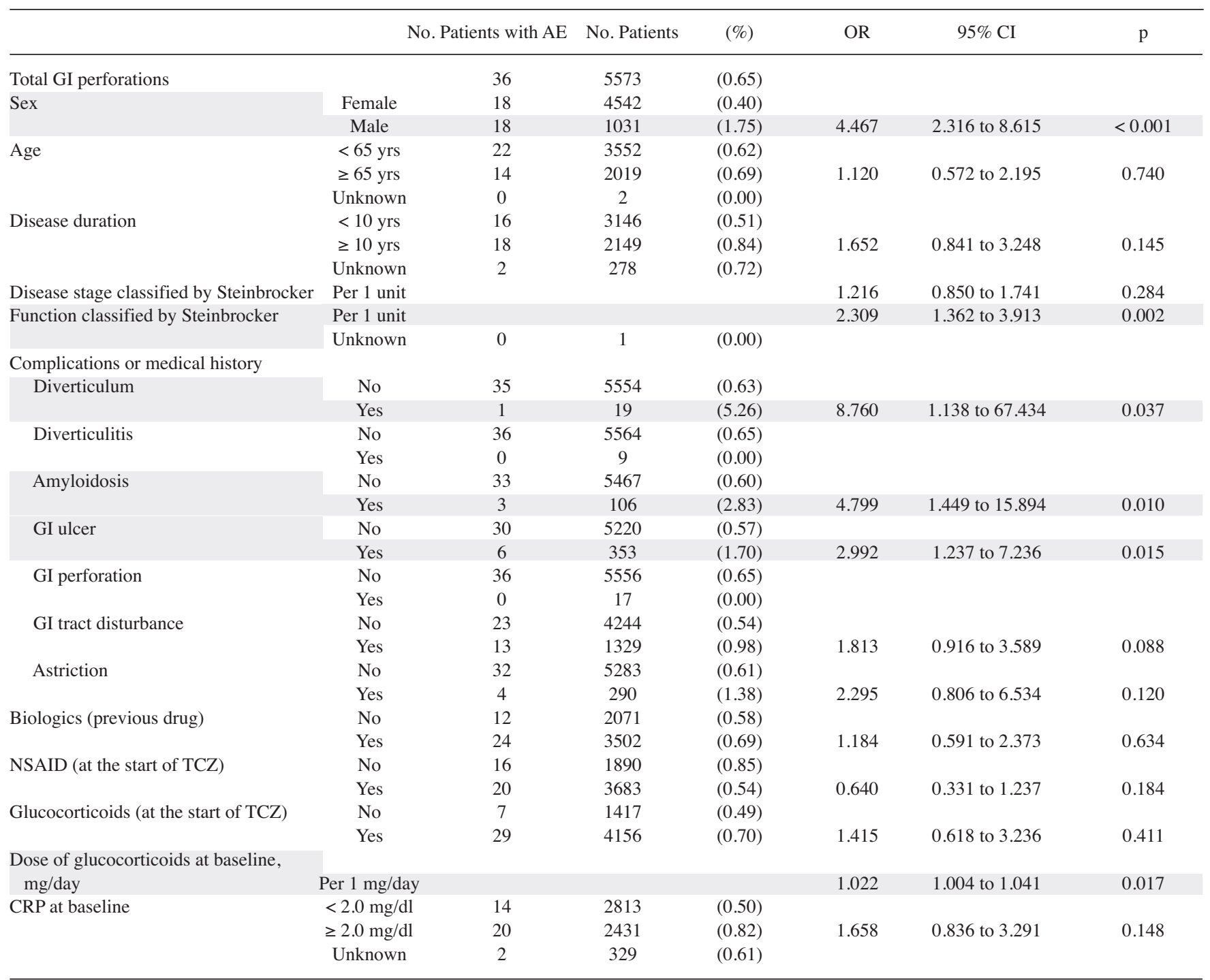

\footnotetext{
${ }^{a}$ Multiple classification analysis did not reveal that the number of GI perforations was too small for reliable analysis. Highlighted cells indicate covariates that were significant predictors of GI perforation. AE: adverse event; CRP: C-reactive protein; GI: gastrointestinal; NSAID: nonsteroidal antiinflammatory drugs; TCZ: tocilizumab.
} 